\title{
Microrelief-Controlled Overland Flow Generation: Laboratory and Field Experiments
}

\author{
Xuefeng Chu, G. Padmanabhan, and Daniel Bogart \\ Department of Civil and Environmental Engineering, North Dakota State University, Department 2470, \\ P.O. Box 6050, Fargo, ND 58108-6050, USA
}

Correspondence should be addressed to Xuefeng Chu; xuefeng.chu@ndsu.edu

Received 3 December 2014; Accepted 24 February 2015

Academic Editor: Davey Jones

Copyright (C) 2015 Xuefeng Chu et al. This is an open access article distributed under the Creative Commons Attribution License, which permits unrestricted use, distribution, and reproduction in any medium, provided the original work is properly cited.

Surface microrelief affects overland flow generation and the related hydrologic processes. However, such influences vary depending on other factors such as rainfall characteristics, soil properties, and initial soil moisture conditions. Thus, in-depth research is needed to better understand and evaluate the combined effects of these factors on overland flow dynamics. The objective of this experimental study was to examine how surface microrelief, in conjunction with the factors of rainfall, soil, and initial moisture conditions, impacts overland flow generation and runoff processes in both laboratory and field settings. A series of overland flow experiments were conducted for rough and smooth surfaces that represented distinct microtopographic characteristics and the experimental data were analyzed and compared. Across different soil types and initial moisture conditions, both laboratory and field experiments demonstrated that a rough soil surface experienced a delayed initiation of runoff and featured a stepwise threshold flow pattern due to the microrelief-controlled puddle filling-spilling-merging dynamics. It was found from the field experiments that a smooth plot surface was more responsive to rainfall variations especially during an initial rainfall event. However, enhanced capability of overland flow generation and faster puddle connectivity of a rough field plot occurred during the subsequent rain events.

\section{Introduction}

Surface microrelief is one of the major factors that control overland flow generation, surface runoff, and other related processes. Under the influence of surface microrelief, overland flow generation and the runoff process can be characterized as four successive stages: infiltration-dominated stage, puddle-to-puddle (P2P) filling-spilling-merging stage, transition stage, and steady-state stage. During the P2P stage, excess rain water begins to fill depressions that eventually spill when the ponded water level reaches the maximum depression storage, which further triggers threshold flow, merging of puddles, and cascaded drainage towards the final outlet of the surface [1]. During this phase, contributing areas expand as hydrologic connectivity is strengthened. Studies have been conducted to understand how and to what extent surface microrelief affects hydrologic processes and to further evaluate the influences. Due to the associated P2P processes, microrelief can directly control overland flow including its spatiotemporal distributions (initiation time, temporal variations, and water depths) and its movement (flow directions, accumulations, and velocities) [1-9]. Variations in surface microtopography affect infiltration and soil water dynamics, which in turn influences surface runoff [10]. Microrelief determines the drainage pattern [11] and even the structure of the drainage system [1]. Surface microrelief also influences runoff (its initiation, flow dynamics, and retention) indirectly through depression storage and surface ponding [9-13].

Concerning overland flow production from rough and smooth surfaces featuring dissimilar microtopographic characteristics, a common question is which surface (rough or smooth) generates more runoff? Intuitively, a rough surface is expected to generate less surface runoff due to its larger depression storage capacity. However, mixed findings associated with this question have been obtained from various experimental studies. Under certain circumstances, a rough soil surface showed higher potential and increased capability of overland flow generation and did produce more surface 
TABLE 1: Details on the laboratory overland flow experiments.

\begin{tabular}{lcccc}
\hline Experiment number & Soil type & Rainfall intensity $(\mathrm{cm} / \mathrm{hr})$ & Initial water content $\left(\mathrm{cm}^{3} / \mathrm{cm}^{3}\right)$ & Surface microrelief \\
\hline 1 & Silty clay & 5.95 & 0.120 & Rough and smooth \\
2 & Silty clay loam & 5.95 & 0.139 & Rough and smooth \\
3 & Loamy sand & 5.95 & 0.144 & Rough and smooth \\
4 & Silty clay & 5.95 & 0.165 & Rough and smooth \\
5 & Silty clay & 5.95 & 0.207 & Rough and smooth \\
6 & Silty clay & 3.54 & 0.145 & Rough and smooth \\
7 & Silty clay & $5.95-1.16-3.54-5.95$ & 0.213 & Rough and smooth \\
8 & Silty clay & $5.95-0-5.95-0-5.95$ & 0.226 & Rough and smooth \\
\hline
\end{tabular}

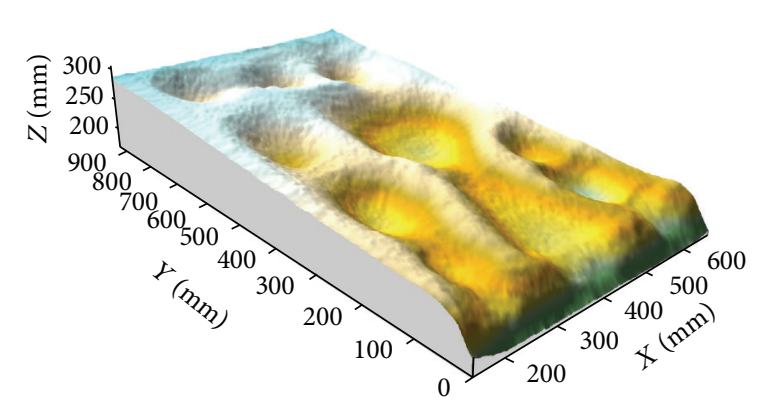

(a) Laboratory rough (LR) surface

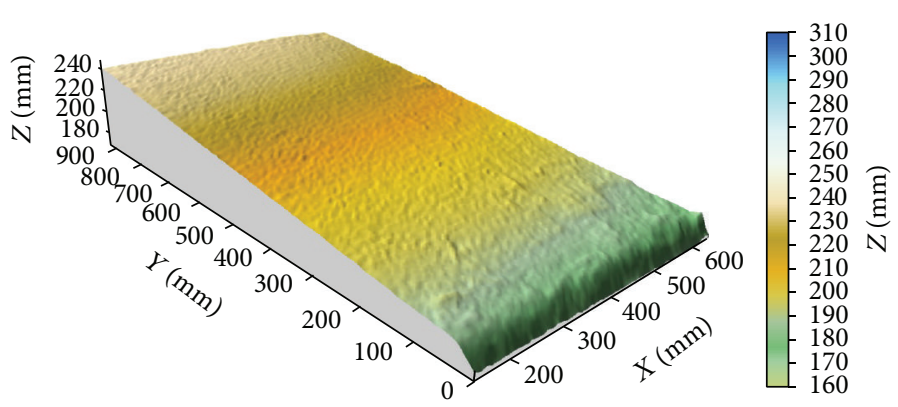

(b) Laboratory smooth (LS) surface

FIGURE 1: Rough and smooth soil surfaces used for laboratory overland flow experiments.

runoff $[14,15]$. Importantly, the influences of surface microrelief on overland flow generation and the related hydrologic processes vary depending on other factors such as rainfall, soil, and initial soil moisture conditions. However, few studies have been conducted to examine the combined effects of these factors on overland flow dynamics. This study focused on examining overland flow generation under the influence of surface microrelief through a series of laboratory and field experiments. The objective of this study was to evaluate the combined effects of microtopographic characteristics, soil properties, rainfall features, and initial soil moisture conditions on overland flow and runoff processes. The experimental scenarios involved combinations of laboratory- and field-scale rough and smooth soil surfaces, three soil types of different textures, and three different initial soil moisture conditions, as well as four simulated/natural, single/multiple, and steady/unsteady rainfall events.

\section{Materials and Methods}

2.1. Laboratory Overland Flow Experiments. A series of experiments were conducted in a controlled laboratory setting to examine the effects of surface microrelief on overland flow generation in conjunction with other important factors that control surface runoff and infiltration processes, including soil type, soil moisture, and rainfall conditions. For comparison purposes, both rough and smooth surfaces (Figure 1) were replicated and used in the experiments. Table 1 summarizes the eight laboratory experiments that combined different soil types, initial soil moisture conditions, and rainfall characteristics. In particular, each experiment included both rough and smooth soil surfaces. To control these variables and quantify their influences on runoff generation, detailed experimental procedures were implemented, which involved soil processing, soil packing, replication of surface microrelief, and surface scanning, as well as data collection and processing. An instantaneous-profile laser scanner $[3,8]$ was utilized to acquire high-resolution DEMs of the microtopographic surfaces and a Norton-style fourhead rainfall simulator $[16,17]$ was used to generate varying intensity rainfall events for the overland flow experiments listed in Table 1.

Three different soils were used for the experiments in this study. They included silty clay $(4.2 \%$ sand, $46.7 \%$ silt, and $49.1 \%$ clay), silty clay loam (11.1\% sand, $60.1 \%$ silt, and $28.8 \%$ clay), and loamy sand ( $80.3 \%$ sand, $14.6 \%$ silt, and $5.1 \%$ clay). The bulk density values of the silty clay, silty clay loam, and loamy sand soils were $1.00,1.07$, and $1.40 \mathrm{~g} / \mathrm{cm}^{3}$, respectively. The silty clay and silty clay loam were both extracted from a farm near Buxton, ND, while the loamy sand was obtained from Ulen, MN. The soils were sifted through a $2 \mathrm{~mm}$ screen. For each experiment, a calculated volume of water was added to the processed soil to achieve the desired initial water content. Before packing, a soil sample was taken to measure the final moisture content.

The soil box was $120 \mathrm{~cm} \times 100 \mathrm{~cm}$. To facilitate a side-byside comparison of dissimilar microtopographic conditions (rough and smooth surfaces, Figure 1) under the same rainfall, the soil box was partitioned into two separate chambers, each of which had an equal surface area of $60 \mathrm{~cm} \times 100 \mathrm{~cm}$. To ensure the same surface microtopography for comparison purpose, detachable molds were used to replicate rough 


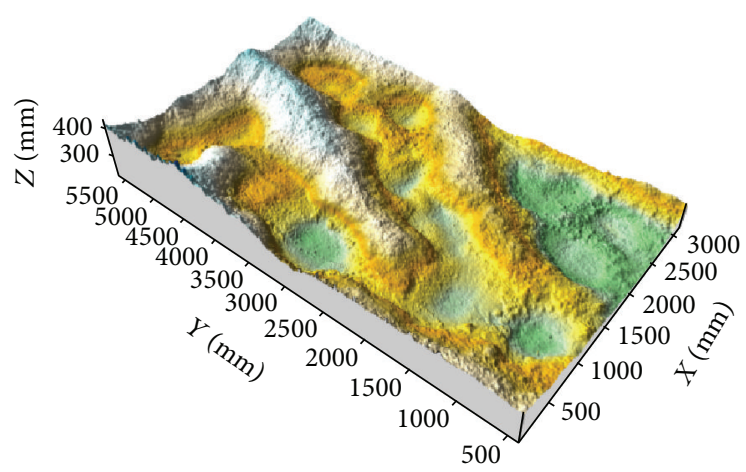

(a) Field rough (FR) surface

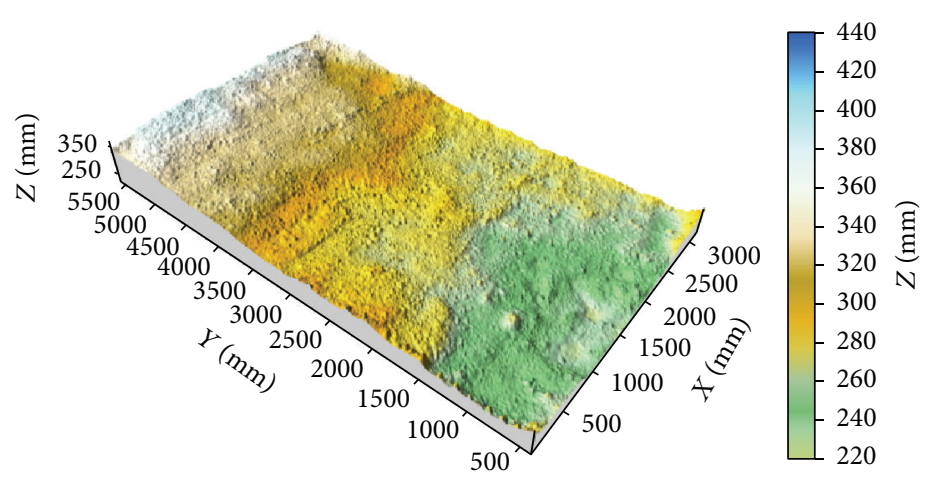

(b) Field smooth (FS) surface

Figure 2: Rough and smooth field plots used for field overland flow experiments.

and smooth soil surfaces for different experiments and a special hoist system was utilized to rotate the soil box for soil packing [18]. Soil was packed into the two chambers of the box layer-by-layer based on the program-determined volumes. This new soil packing method ensured a uniform bulk density across the entire soil box [18]. Both rough and smooth surfaces were scanned by using the instantaneousprofile laser scanner to create their high-resolution DEMs.

The Norton-style four-head rainfall simulator was utilized to generate rainfall that varied in intensity and duration $[16,17]$, depending on the design of the overland flow experiments. During an experiment, discharges at the outlets of both the rough and smooth surfaces were measured; wetting front depths on the sides of the soil box were marked; and surface ponding and puddle filling-spillingmerging were recorded. The experiment continued until the outlet discharge appeared steady.

Comparison of Experiments 1-3 (Table 1) was performed for the three soil types. To evaluate the effects of initial soil moisture, three different initial water contents were considered in Experiments 1,4 , and $5\left(\theta_{1}=0.120, \theta_{2}=\right.$ 0.165 , and $\theta_{3}=0.207$, resp.) (Table 1 ) and their experimental results were compared. Experiments 1, 6, 7, and 8 represented four different rainfall conditions, including single heavy and moderate steady rainfall events (Rain 1: $5.95 \mathrm{~cm} / \mathrm{hr}$ and Rain 2: $3.54 \mathrm{~cm} / \mathrm{hr}$ ), a single unsteady rainfall event (Rain 3: 5.95$1.16-3.54-5.95 \mathrm{~cm} / \mathrm{hr}$ ), and a complex rainfall pattern that consisted of a set of wet and dry periods (Rain 4: 5.95-0-5.95$0-5.95 \mathrm{~cm} / \mathrm{hr}$ ) (Table 1). Comparison of these four experiments provided insight into the influences of rainfall intensity and pattern, in conjunction with surface microrelief (both rough and smooth soil surfaces), on overland flow generation.

In addition, to further evaluate the significance in the differences of outlet discharges between the smooth and rough soil surfaces (i.e., effect of surface microtopography), a paired $t$-test was performed with a criterion of $\alpha=0.05$ (i.e., probability $P=0.05$ ) for all pairs of outlet discharges from the smooth and rough soil surfaces in the eight experiments (Table 1) that involved comparisons of three different soil types, three different initial moisture conditions, and four different rainfall characteristics.
2.2. Quantification of Rainfall-Induced Changes in Surface Microtopography. During an overland flow experiment, surface microtopography may change due to the raindrop effect and the related soil erosion and sediment transport processes. Particularly, deposition may occur in surface depressions/puddles. To evaluate such changes in surface microtopography and their potential influence on overland flow generation, a rough surface (Figure 1(a)) was created by using the detachable mold. The silty clay loam soil of an initial water content of $0.174 \mathrm{~cm}^{3} / \mathrm{cm}^{3}$ was used and a steady rainfall with an intensity of $3.46 \mathrm{~cm} / \mathrm{hr}$ was applied. The experiment lasted $40 \mathrm{~min}$. The soil surface was scanned by using the instantaneous-profile laser scanner before and after the rainfall event, from which both pre- and postrainfall DEMs were obtained.

Chu et al. [19] developed a new algorithm for puddle delineation (PD). The Windows-based PD program facilitates automated DEM-based surface delineation, including determination of flow directions and accumulations, identification of depressions/puddles (e.g., their centers, overflow thresholds, levels, and hierarchical relationships), computation of microtopographic parameters such as maximum depression storage (MDS) and maximum ponding area (MPA), and visualization of the delineation results. The PD program has been used for a variety of microtopographic surfaces [1]. In this study, the PD program was utilized for characterizing the microtopographic features of the two scanned surfaces (preand postrainfall surfaces) to quantitatively assess the changes in surface microtopography induced by rainfall.

2.3. Field Overland Flow Experiments. Two field plots were created at the Main Station of the North Dakota Agricultural Experiment Station in Fargo. Each plot was $6.0 \mathrm{~m} \times 3.5 \mathrm{~m}$. As shown in Figure 2, the two plot surfaces had distinct microtopographic characteristics (rough and smooth). The rough surface (Figure 2(a)) featured a number of depressions and mounds, while the smooth one (Figure 2(b)) was essentially an inclined plane surface with a certain degree of natural surface roughness primarily associated with soil clods or aggregates. The soil of the two field plots consisted of $17.5 \%$ of silt and $82.5 \%$ of clay. Both plot surfaces had an overall slope of $2.5 \%$ towards their outlets where surface runoff was 
collected and recorded. The field plots were covered with large tarps between rain events to protect the surfaces.

To characterize surface microrelief, each field plot surface was scanned by using the instantaneous-profile laser scanner. Due to the size of the surface, only a small section of the plot was scanned each time. The laser scanner was then slid down a rail system to obtain the next "strip" of DEM data until the entire plot surface was scanned. During the scanning process, overlapping was insured for any adjacent strips. The pieceby-piece scanned data were eventually synthesized into one DEM by using a Windows-based program specially developed for automatic combination of scanned DEM data. In the field plots, five locations that represented upstream/downstream and depression/mound locations and two depths (5 and $10 \mathrm{~cm}$ ) at each location were selected for collecting soil moisture data. Decagon ECH2O EC-5 moisture sensors were installed to continuously measure soil water contents. In addition, a tipping bucket rain gauge (HOBO data logging rain gauge, RG3) also was installed in the field to collect rainfall data.

Field overland flow experiments were conducted for two rainfall events. The first rain event on June 26, 2011, lasted about $26 \mathrm{~min}$ with a cumulative amount of $0.559 \mathrm{~cm}$, while the cumulative rainfall of the second event on August 12, 2011, was $0.508 \mathrm{~cm}$ during a period of $42 \mathrm{~min}$. Thus, the two events had dissimilar features (Event 1: short-duration heavy rainfall; Event 2: long-duration light rainfall). During these two rainfall events, discharge was collected and measured at the outlet of each field plot at constant time intervals and their hydrographs were generated. Particularly, surface ponding, puddle filling, puddle spilling (threshold overflow), and puddle merging also were observed and recorded for the rough field plot. The data were used for analyzing the P2P filling-spilling-merging dynamics, hydrologic connectivity, and other hydrologic processes related to overland flow generation.

\section{Results and Discussion}

\subsection{Analysis of Laboratory Experiments}

3.1.1. Soil Type Scenarios. Experiments 1-3 (Table 1) involved three different soil types (silty clay, silty clay loam, and loamy sand) under the same rainfall $(5.95 \mathrm{~cm} / \mathrm{hr})$. Figure 3 shows the comparison of the observed hydrographs of the rough and smooth surfaces for Experiments 1-3. As expected, much higher surface runoff was generated from the finer textured soils (silty clay and silty clay loam) for both rough and smooth surfaces (Figure 3). For all the three soil types, a delayed initiation of surface runoff can be observed for the rough surfaces due to the effect of surface depressions. For the two finer soils, the smooth surfaces yielded more surface runoff. The hydrographs of their rough and smooth surfaces were characterized by a sharp increase almost immediately after runoff began at the outlets. After the 1-hour duration, the outlet discharge for Experiments 1 and 2 approached a relatively steady state (Figure 3). For the coarse soil of Experiment 3 (loamy sand), however, different changing patterns can be observed in the hydrographs. The primary

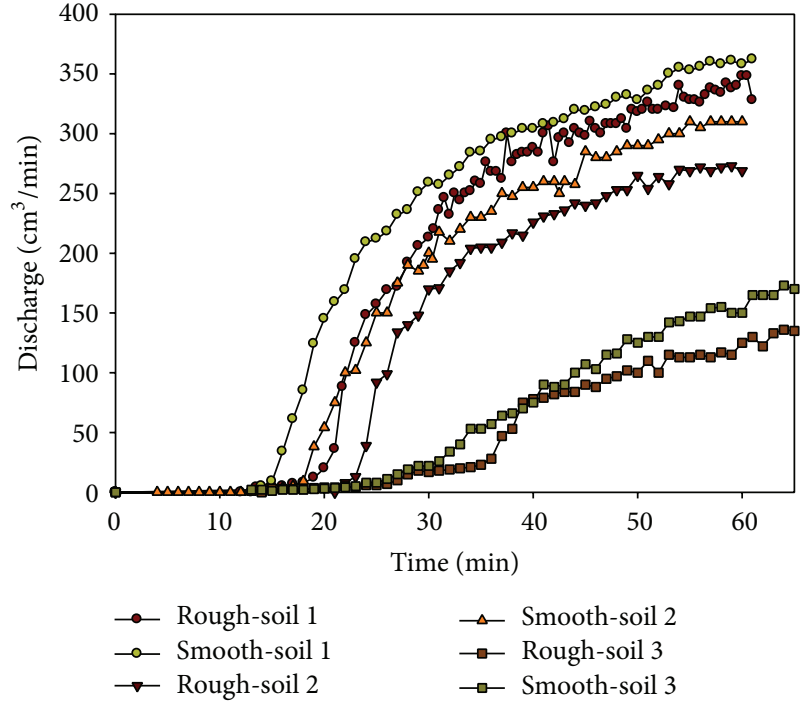

FIGURE 3: Observed hydrographs of the laboratory rough and smooth surfaces for three soil types (Soil 1: silty clay; Soil 2: silty clay loam; and Soil 3: loamy sand).

runoff commenced much later for both rough and smooth surfaces and the outlet discharges increased much slower (Figure 3). Importantly, two stepwise increases associated with the P2P process and threshold flow can be observed in the hydrograph of the rough surface around 30 and $40 \mathrm{~min}$ (Figure 3). At $t=40 \mathrm{~min}$, the discharge from the rough surface was even greater than the one from the smooth surface (Figure 3). The hydrographs of both rough and smooth surfaces took a much steadier rise after initial runoff occurred at the outlets and showed a continuous increase as Experiment 3 for the loamy sand soil ended at $t=80 \mathrm{~min}$. According to the paired $t$-test, the $t$ values for the three soil types (silty clay, silty clay loam, and loamy sand) were 8.701, 14.528 , and 10.487, respectively, with $P<0.001$, indicating that the difference or change in the outlet discharges from the smooth and rough soil surfaces was statistically significant for all three soil types. The results also demonstrated the significant effects of surface microtopography on overland flow generation.

Hydrologic connectivity for the rough surfaces in Experiments 1 and 2 (finer soils, Table 1) was observed. Specifically, the expansion of contributing areas and puddle filling, spilling, and merging during the rainfall events were recorded and analyzed. For these two experiments, most puddles were fully filled and threshold flow occurred between 19 and 25 min. For Experiment 3 (coarser soil), however, puddle threshold spilling events and the corresponding stepwise changes in the hydrograph were observed at $t=29-36$ minutes (Figure 3). Rough surfaces exhibited certain delays in runoff production, depending upon the level of roughness and apparently their soil type. The low permeability of the finer textured soils (silty clay and silty clay loam) caused earlier ponding and thus earlier threshold flow, inducing "quicker" hydrologic connectivity. Because the puddle fillingspilling-merging processes were completed within a much 


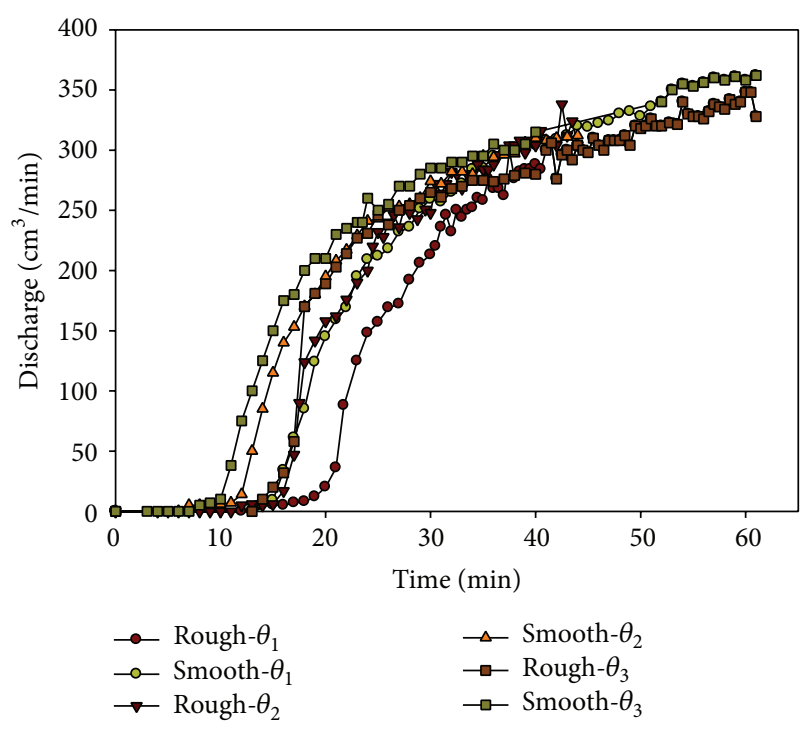

Figure 4: Observed hydrographs of the laboratory rough and smooth surfaces for three soil moisture conditions $\left(\theta_{1}=0.120\right.$; $\theta_{2}=0.165$; and $\left.\theta_{3}=0.207\right)$.

shorter time for these two finer soils, their hydrographs did not exhibit obvious stepwise changes that were observed in the hydrograph of the loamy sand (coarser textured soil) (Figure 3). In contrast, all smooth surfaces began to contribute runoff after ponding and their hydrographs displayed a steady rise, reflecting the gradual expansion of the contributing areas or increase in hydrologic connectivity until eventually leveling off due to full connectivity. The results of Experiments 1-3 indicated that soil type, in conjunction with surface microrelief, affected hydrologic connectivity and the characteristics of the associated hydrographs.

3.1.2. Initial Soil Moisture Scenarios. The silty clay soil was utilized in Experiments 1, 4, and 5 under the same steady rainfall $(5.95 \mathrm{~cm} / \mathrm{hr})$. However, initial moisture conditions were different in these three experiments (Table 1). Figure 4 shows the comparison of the hydrographs of both rough and smooth surfaces for the three different initial water contents. Increasing the moisture content from $\theta_{1}=0.120$ to $\theta_{2}=0.165$ and $\theta_{3}=0.207$ caused earlier initiation and faster runoff generation on both rough and smooth surfaces (Figure 4). However, after $45 \mathrm{~min}$, the differences in the hydrographs of the rough or smooth surfaces for the three initial soil moisture conditions gradually disappeared (Figure 4). That is, the influence of initial soil moisture on the outlet discharge tended to become less important as wetting front moved to deep soil over time. In all cases, the rough surface maintained a flow rate lower than the corresponding smooth surface. Based on the paired $t$-test, the $t$ values for the three initial soil water contents $\left(\theta_{1}=0.120, \theta_{2}=0.165\right.$, and $\theta_{3}=$ 0.207 ) were $8.701,4.633$, and 6.244 , respectively, with $P<$ 0.001 , indicating that the difference in the outlet discharges between the smooth and rough soil surfaces was statistically significant under different initial moisture conditions.
3.1.3. Rainfall Scenarios: Single Steady Rain Events. Experiments 1, 6, 7, and 8 involved overland flow generation from both rough and smooth surfaces under different rainfall intensities and changing patterns (Table 1). Figure 5(a) displays the comparison of hydrographs of both rough and smooth surfaces for the heavy and moderate rainfall events. As expected, the heavier rainfall $(5.95 \mathrm{~cm} / \mathrm{hr})$ of Experiment 1 generated much higher overland flow than the moderate rainfall $(3.54 \mathrm{~cm} / \mathrm{hr})$ in Experiment 6 for both rough and smooth surface even though the initial moisture content of Experiment 6 was higher (Figure 5(a)). In addition, significant delay in runoff initiation can be observed for the lower intensity rainfall, especially for the rough soil surface. It also took longer time to reach a steady flow at the outlet for a lighter rainfall. In both cases of rainfall, the rise in outlet flow from the rough surface was delayed compared with the smooth surface. The hydrograph of the rough surface for this moderate rainfall in Experiment 6 also exhibited a stepwise changing pattern associated with threshold flow (Figure 5(a)). Under this moderate rainfall, the smooth surface generated more surface runoff before $45 \mathrm{~min}$. Interestingly, however, the rough surface overtook the smooth surface in runoff generation after $50 \mathrm{~min}$ (Figure 5(a)). This phenomenon also has been observed in the field experiments discussed in the following section. Based on the paired $t$-test, the $t$ values for these two single steady rainfall events $(5.95$ and $3.54 \mathrm{~cm} / \mathrm{hr})$ were $8.701(P<0.001)$ and $-3.423(P=0.002)$, indicating that the difference in the outlet discharges between the smooth and rough soil surfaces was statistically significant for both steady rain events.

Similar to the comparison of the results for Experiments $1-3$, there was a difference in the range of time for hydrologic connectivity of the rough surface. Under the heavy rainfall in Experiment 1, the rough surface experienced delayed incipient runoff due to low hydrologic connectivity. Then, the flow at the outlet began to rise as hydrologic connectivity increased at $t$ equal to 12-19 min (Figure 5(a)). This quick transition from low to high hydrologic connectivity over the rough surface resulted in a smoother hydrograph that was comparable to that of the smooth surface. In contrast, the rough surface under the moderate rainfall in Experiment 6 experienced most of its hydrologic connectivity over the surface in the time range of 33 to $53 \mathrm{~min}$ and its hydrograph featured a certain stepwise increasing pattern (Figure 5(a)).

3.1.4. Rainfall Scenarios: Single Unsteady Rain Event. Figure 5(b) displays the hydrographs of the rough and smooth surfaces under the unsteady rainfall event (Rain 3) in Experiment 7. Complex changes in discharge can be observed due to the variations in rainfall intensity and the resulting shift between ponding and nonponding conditions. The rainfall began at an intensity of $5.95 \mathrm{~cm} / \mathrm{hr}$ over both smooth and rough surfaces and continued until the entire areas contributed runoff to the outlets. The first portion of the hydrographs (Figure 5(b)) shows a typical comparison of discharges from the rough and smooth surfaces under the first rain intensity. The slower connectivity of the rough surface induced by surface depressions delayed the rise in its outlet discharge. However, at full hydrologic connectivity 


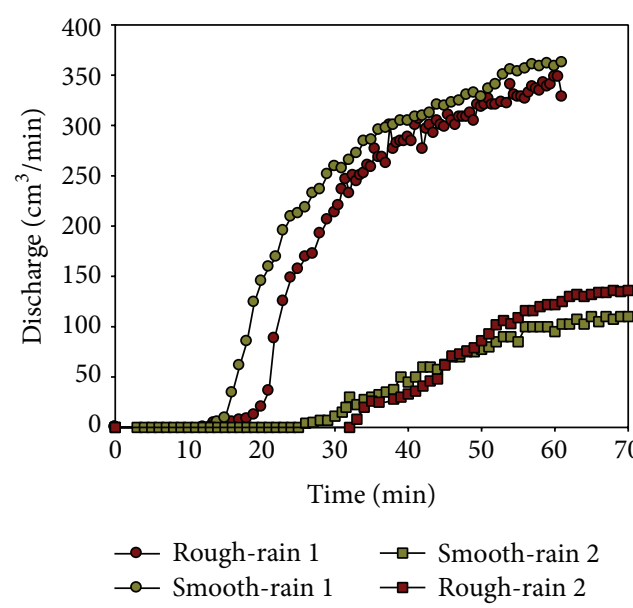

(a) Steady rain

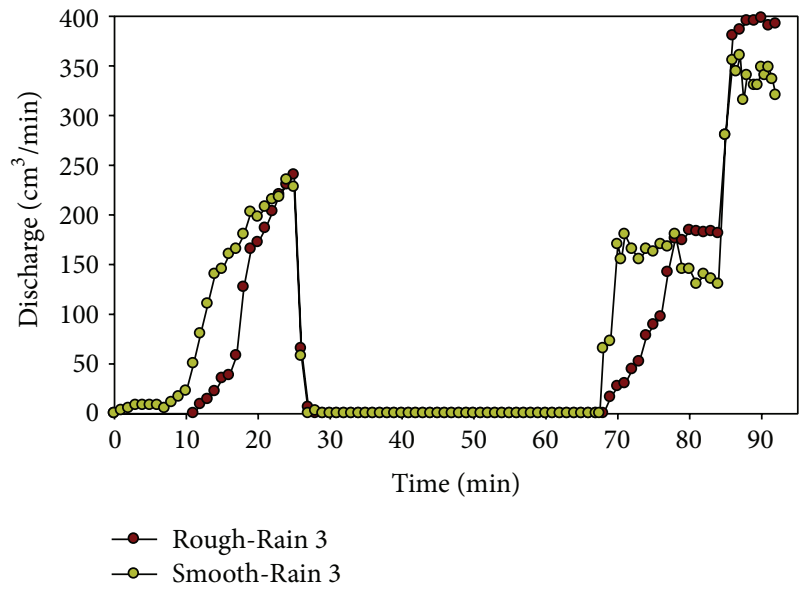

(b) Unsteady rain

FIGURE 5: Observed hydrographs of the laboratory rough and smooth surfaces for two steady rainfall events (Rain 1: $5.95 \mathrm{~cm} / \mathrm{hr}$ and Rain 2: $3.54 \mathrm{~cm} / \mathrm{hr}$ ) and one unsteady rainfall event (Rain 3: 5.95-1.16-3.54-5.95 cm/hr).

over the surface at $t=25 \mathrm{~min}$, the rough and smooth surfaces yielded comparable discharges. After that time, the rainfall intensity was set to $1.16 \mathrm{~cm} / \mathrm{hr}$, which was lower than the infiltration capacity. Except for the puddle areas, both surfaces quickly shifted to a nonponding condition. The water stored in depressions on the rough surface began to decrease due to infiltration. After $42.5 \mathrm{~min}$ under this low intensity rainfall, the depression storage of the rough surface became zero. Once the entirety of both surfaces had no ponded water, the rainfall intensity was then increased to $3.54 \mathrm{~cm} / \mathrm{hr}$. This rainfall intensity was higher than the infiltration capacity at that time and hence caused an instantaneous ponding condition on both surfaces. The hydrograph of the smooth surface indicated that the surface reached full hydrologic connectivity within a couple of minutes (Figure 5(b)). The discharge from the rough surface also increased and reached a fully contributing stage in about 10 minutes (Figure 5(b)). Both surfaces reached a steady flow of approximately $180 \mathrm{~cm}^{3} / \mathrm{min}$ with some variations observed for the smooth surface. At $t=85 \mathrm{~min}$, the rainfall intensity was set to $5.95 \mathrm{~cm} / \mathrm{hr}$, which was applied until an apparent steady flow on both surfaces was evident (8 minutes) and then the experiment ended. During this final stage, the rough surface generated markedly higher runoff than the smooth one (Figure 5(b)). This again demonstrated that, under certain timing and circumstances (combination of soil properties, moisture conditions, and rainfall characteristics), a rough soil surface could generate comparable or even higher surface runoff compared to the smooth one. This finding is consistent with that from the field study detailed in the following section. The $t$ value for this single unsteady rainfall event was $2.456(P=0.016)$, indicating that the difference in the outlet discharges between the smooth and rough soil surfaces was statistically significant.

3.1.5. Rainfall Scenarios: Multiple Rain Events. Figure 6 shows the observed hydrographs of the rough and smooth surfaces for the complex rainfall in Experiment 8 that consisted of three stages of rainfall alternating between wet and dry time periods (Rain 4: $5.95-0-5.95-0-5.95 \mathrm{~cm} / \mathrm{hr}$ ). The characteristics of the hydrographs of the rough and smooth surfaces for the first event of this complex rainfall series in Experiment 8 (Figure 6(a)) were similar to those observed for the first rainfall intensity of the unsteady rainfall event in Experiment 7 (Figure 5(b)). The rough surface showed a delayed initiation of surface runoff, compared with the smooth one. Similar to Experiment 7, the discharges from the rough and smooth surfaces eventually became comparable after complete hydrologic connectivity was achieved (Figure 6(a)). The second rain event started at $t=320 \mathrm{~min}$. Surface runoff from both rough and smooth surfaces quickly increased and the outlet discharges reached a steady state in about 10 minutes (Figure 6(b)). Similar to the last stage of the unsteady rainfall event (Rain 3) in Experiment 7 (Figure 5(b)), the rough surface yielded a higher steady flow rate by the end of Event 2 (Figure 6(b)). For Event 3 that started at $t=1100 \mathrm{~min}$, the hydrographs of the rough and smooth surfaces showed a much shorter runoff initiation time, a steeper increase, and higher steady flow rate (Figure 6(c)). A more significant discrepancy in the final discharges can be observed between the rough and smooth surfaces (Figure 6(c)). Thus, the experimental data for multiple rain events strongly suggested that, during the initial rainfall event, the smooth surface generated higher runoff compared to the rough one. However, higher runoff was generated from the rough surface during the later stage of the subsequent rain events and the difference in steady flows between the rough and smooth surfaces gradually increased. Overland flow generation in the subsequent rain events featured a shorter initiation time and a quicker and higher flow for both rough and smooth surfaces. According to the paired $t$-test, the $t$ values for the three events of this complex rainfall were $1.607(P=0.118), 0.035(P=$ $0.972)$, and $-1.125(P=0.281)$, respectively, indicating that the difference or change in the outlet discharges between 


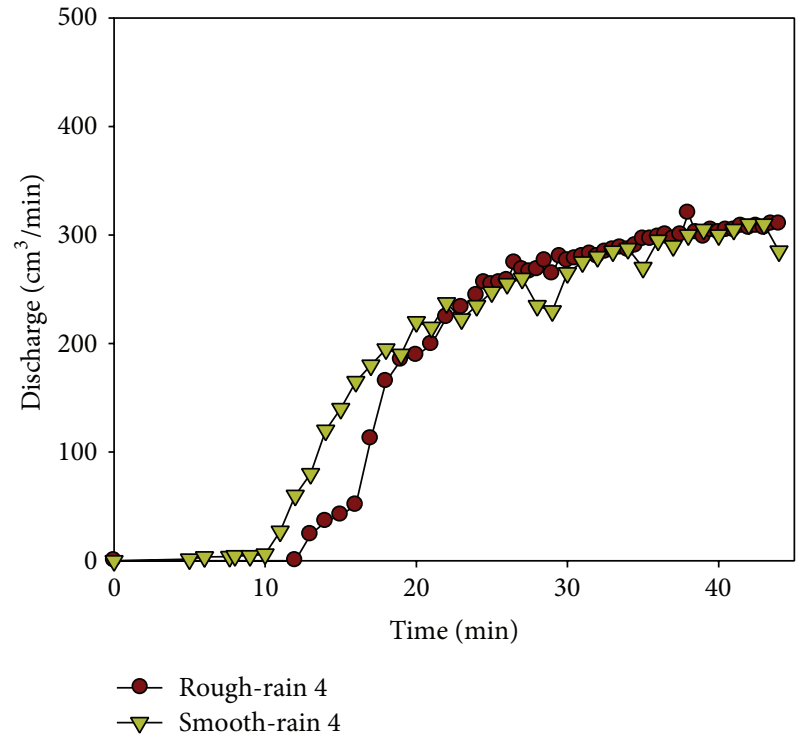

(a) Event 1

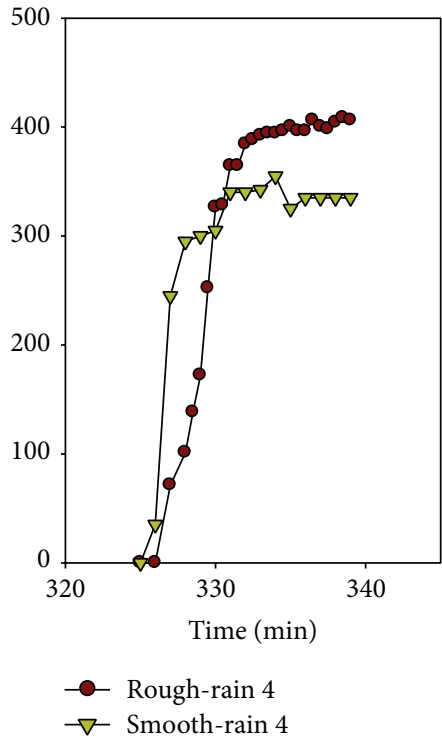

(b) Event 2

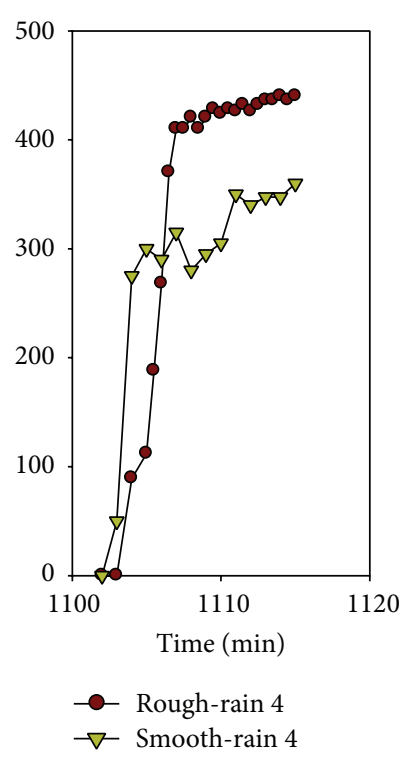

(c) Event 3

FIGURE 6: Observed hydrographs of the laboratory rough and smooth surfaces for a complex rainfall pattern that consists of three stages of rainfall alternating between wet and dry time periods (Rain 4: 5.95-0-5.95-0-5.95 cm/hr).

the smooth and rough soil surfaces was not great enough to exclude the possibility that the difference was due to chance for this multievent rainfall. This statistical analysis again demonstrated that the changes in hydrologic processes induced by multiple rainfall events (e.g., infiltrability, soil moisture contents, and soil water percolation) eventually led to similar overland flow production for the rough and smooth surfaces.

3.2. Evaluation of Rainfall-Induced Changes in Surface Microtopography. Figures 7(a) and 7(b) show the comparison of the pre- and postrainfall surfaces. The delineation results for the pre- and postrainfall surfaces are shown in Figures 7(c) and 7(d), respectively. According to the PD results, MDS reduced from $794.69 \mathrm{~cm}^{3}$ of the prerainfall surface to $660.57 \mathrm{~cm}^{3}$ of the postrainfall surface (i.e., a change of $-16.88 \%$ ); MPA decreased by $3.40 \%$, from $985.75 \mathrm{~cm}^{2}$ to $952.25 \mathrm{~cm}^{2}$; and the surface depression depth (ratio of MDS to the entire surface area) decreased from $1.41 \mathrm{~mm}$ to $1.17 \mathrm{~mm}$ (i.e., a change of $-16.83 \%)$. In spite of these changes, the impact of rainfall on surface microtopography was minimal. Except for slight deposition at the centers of some depressions on the postrainfall surface (Figure 7(b)), the two surfaces looked nearly identical (Figures 7(a) and 7(b)) and no significant changes were observed in the number and distribution of major depressions (Figures 7(c) and 7(d)). This experiment indicated that the overall influence of the rainfall-induced changes in surface microtopography on overland flow generation also should be limited.

\subsection{Analysis of Field Experiments}

3.3.1. Hyetographs and Hydrographs. Two natural rain events on June 26 and August 12, 2011, had sufficient amount of effective rainfall for the field overland flow experiments using both rough and smooth field plots (Figure 2). Figure 8 shows the hyetographs and hydrographs of the rough and smooth field plots for these two real rainfall events. Event 1 on June 26 featured a short-duration heavy rainfall (Figure 8(a)) with an average intensity of $1.28 \mathrm{~cm} / \mathrm{hr}$, while Event 2 on August 12 with an average rainfall intensity of $0.73 \mathrm{~cm} / \mathrm{hr}$ was longer and lighter (Figure 8(b)).

Both field experiments indicated that the smooth plot surface was more responsive to the rainfall changes than the rough one in generating overland flow. That is, the smooth surface responded quicker to the rainfall input and yielded earlier and higher runoff peaks, especially for the first higher-intensity and shorter-duration rainfall event on June 26, 2011 (Figure 8(a)). Both hyetographs (Figure 8) showed initially short but high intensity rainfall, which was followed by an extended period of rainfall with lower intensities. During the initial high intensity period, surface ponding condition occurred on both plots. However, this ponding and eventual surface runoff had different effects on the outlet hydrographs for the rough and smooth plot surfaces. The smooth surface hydrographs for both events showed early peaks that corresponded to the initial heavy rainfall shortly after surface ponding and initiation of overland flow. During the following extended period, as the rainfall intensity dropped or rose for both events, the flows from the smooth plot varied accordingly which reflected the changes in rainfall intensities. Thus, the smooth plot hydrographs largely mirrored the variations of their respective hyetographs with certain delay periods. The outlet discharge from the rough plot, however, experienced a much longer delay and the hydrographs displayed only one major peak (Figure 8). This changing pattern primarily can be attributed to the greater depression storage of the rough field plot. This is in agreement 


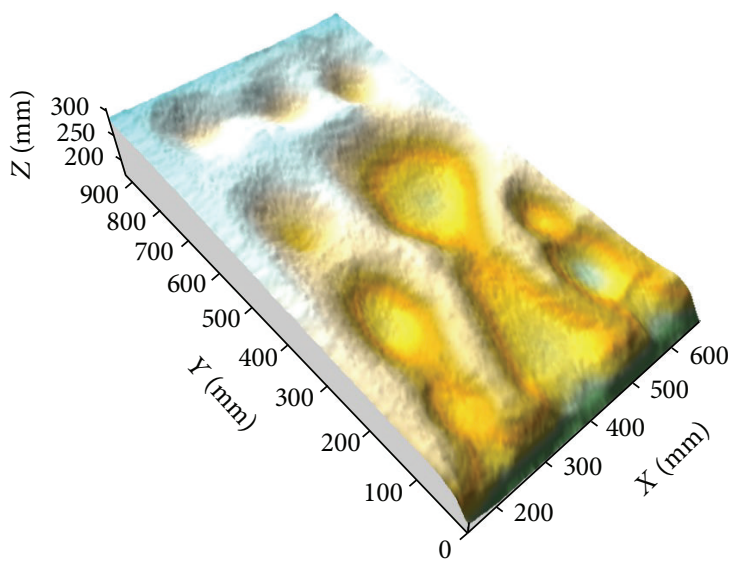

(a) Prerainfall surface

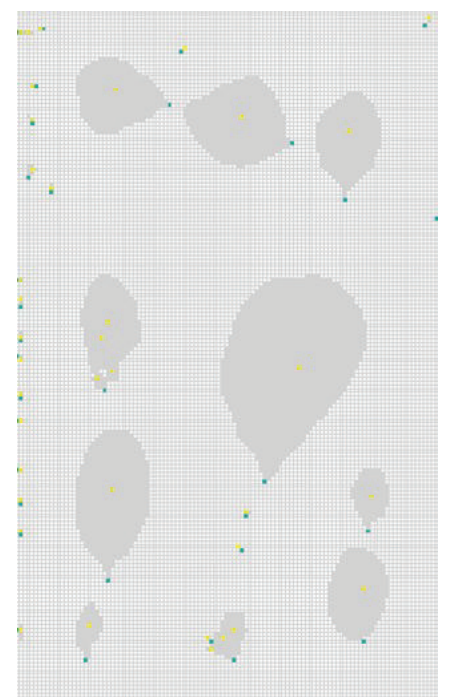

Puddle cell

Puddle center

Puddle threshold

(c) Prerainfall surface delineation

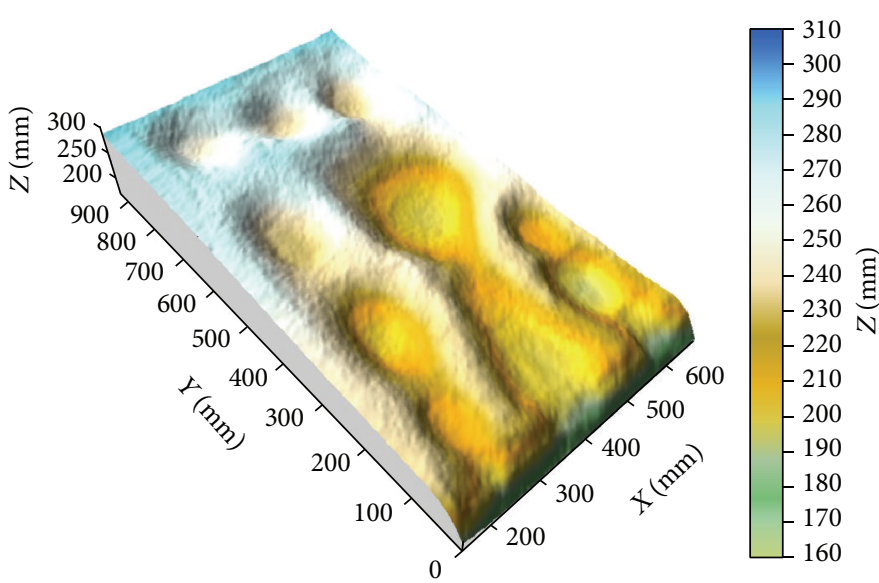

(b) Postrainfall surface

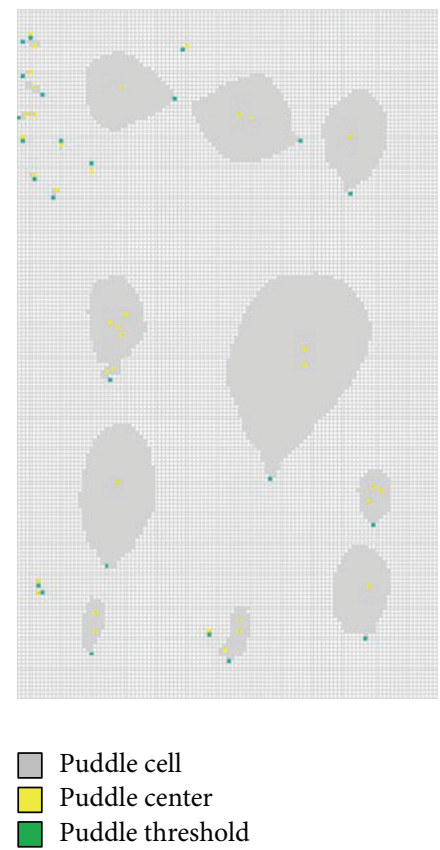

(d) Postrainfall surface delineation

FIGURE 7: Comparison of pre- and postrainfall surfaces and their puddle delineation results.

with the findings of other studies that have suggested that the presence of surface depressions has a delaying effect on the initiation of runoff $[6,14]$. In the recession period of Event 1 (after $15 \mathrm{~min}$ ), the rough and smooth plots yielded comparable discharges (Figure 8(a)). For Event 2, the two heavier rainfalls resulted in two sharp flow peaks on the smooth plot surface. Due to the initial abstraction, the first peak was much lower than the second peak and showed a longer delay although the first heavier rainfall was much greater than the second one (Figure $8(b)$ ). The second heavier rainfall generated a quicker and higher peak flow. In contrast, the first major heavy rainfall of Event 2 only produced little surface runoff from the rough field plot without any obvious peak (Figure 8(b)), mainly due to its greater depression storage. The second major rainfall of Event 2 did generate a significant amount of runoff and the hydrograph exhibited a high crest $(1.0 \mathrm{~L} / \mathrm{min})$ after $30 \mathrm{~min}$, which lasted 4 minutes (Figure $8(\mathrm{~b})$ ). Interestingly, the rough plot yielded higher surface runoff than the smooth one after $36 \mathrm{~min}$ during Event 2 (Figure 8(b)). Hence, these two field experiments demonstrated that the rough surface showed progressively increased reactivity to rainfall changes and elevated capability of runoff production and yielded comparable or even higher surface runoff during the later stage of these real unsteady rainfall events (Events 1 and 2), which was consistent with the findings from the aforementioned laboratory experiments.

3.3.2. Puddle Connectivity and Contributing Area. Figure 9 shows the changes in cumulative outlet discharge and the evolution of contributing area for the rough field plot under both natural rain events (Events 1 and 2). As the cumulative rainfall increased over time, the contributing area expanded 


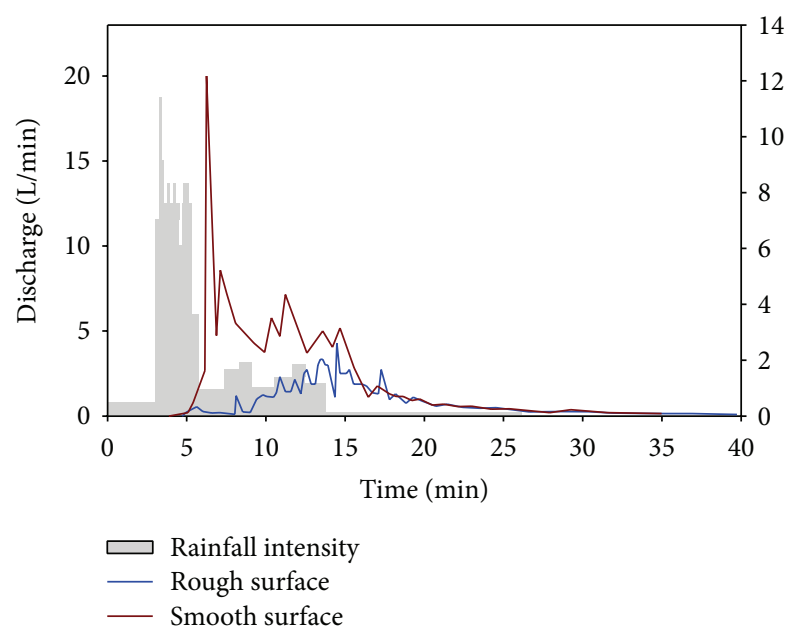

(a) Event 1

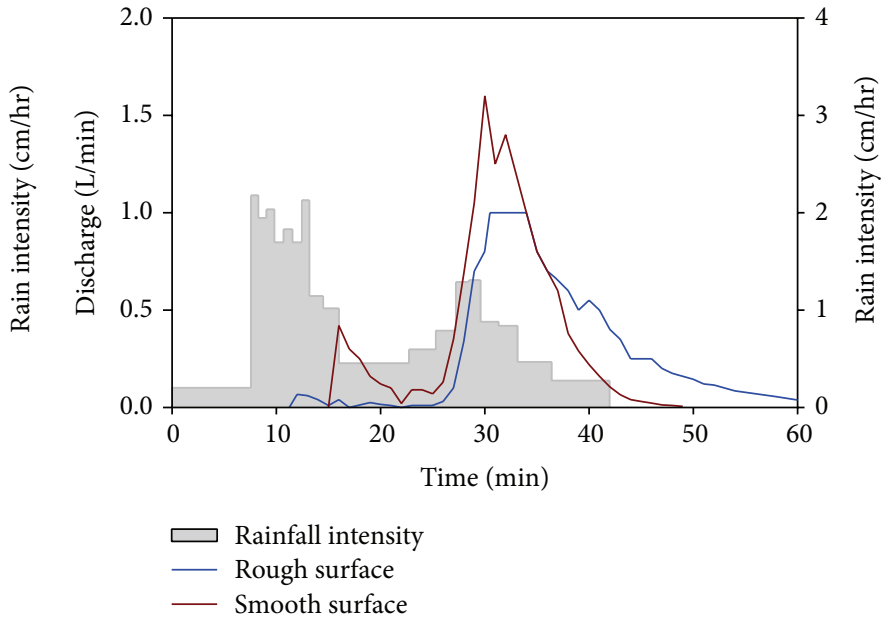

(b) Event 2

Figure 8: Comparisons of observed hydrographs for the rough and smooth field plots under two natural rainfall events (Event 1: shortduration heavy rainfall on June 26, 2011; Event 2: long-duration light rainfall on August 12, 2011).

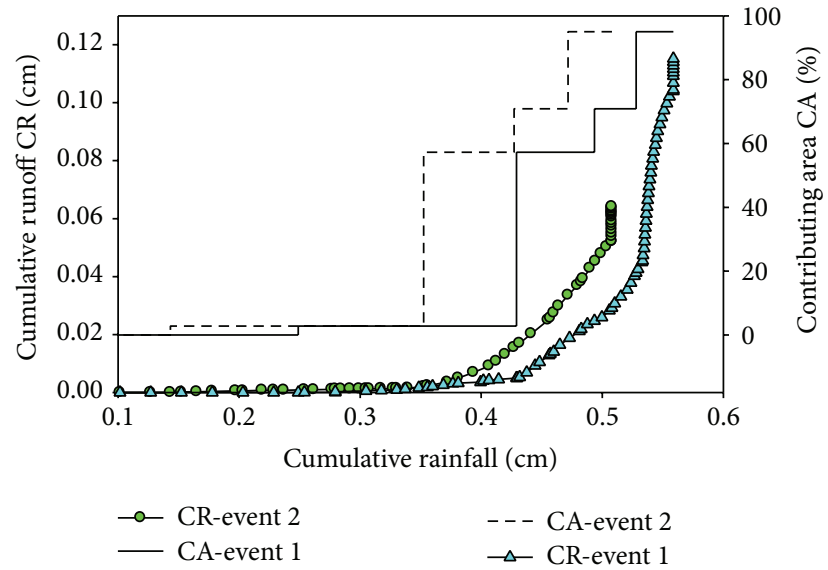

FIGURE 9: Relationships of cumulative rainfall and cumulative runoff $(\mathrm{CR})$ and contributing area $(\mathrm{CA})$ for the rough field plot surface under two natural rainfall events (Event 1: short-duration heavy rainfall on June 26, 2011; Event 2: long-duration light rainfall on August 12, 2011).

in a stepwise increasing pattern that was determined by the surface microrelief of the rough plot surface (Figure 2(a)) and the resultant puddle filling-spilling-merging processes for both rainfall events (Figure 9). Four major stepwise increases in contributing area were observed and their cumulative contributing area percentages were $2.82 \%, 57.28 \%, 70.86 \%$, and $95.03 \%$, respectively (Figure 9). However, the timing of the four stepwise increases in contributing area or threshold flows was different for the two rainfall events. It was interesting that, under the later event (Event 2), a smaller amount of cumulative rainfall was required to achieve puddle spilling or threshold-controlled overflow and puddle connectivity (Figure 9).
In the beginning, contributing area jumped from zero to $2.82 \%$ (Figure 9), which accounted for the small area of the rough plot surface that drained directly to the outlet. The remaining three major increases in contributing area were closely associated with the occurrence of puddle spilling or threshold flow. The first significant increase in contributing area from $2.82 \%$ to $57.28 \%$ occurred when the cumulative rainfall was $0.43 \mathrm{~cm}$ for Event 1 and $0.35 \mathrm{~cm}$ for Event 2 (Figure 9). Note that it took longer time for Event 2 to reach the cumulative amount of $0.35 \mathrm{~cm}$ due to its lower rainfall intensities. It also should be noted that the final connected contributing area of the rough field plot was slightly less than $100 \%$. There was an observable link of the surface connectivity and threshold flows to the cumulative flow at the outlet of the rough field plot for both rainfall events. The first major increase in contributing area for both events (from $2.82 \%$ to $57.28 \%$ ) corresponded to the first significant rise in outlet flow, which also occurred when the cumulative rainfall equaled $0.43 \mathrm{~cm}$ for Event 1 and $0.35 \mathrm{~cm}$ for Event 2 (Figure 9). The coincidence in the two subsequent stepwise increases in contributing area or changes in puddle connectivity and the significant rises in cumulative outlet flows also can be observed in Figure 9 when the cumulative rainfall was 0.49 and $0.53 \mathrm{~cm}$ for Event 1 and 0.43 and $0.47 \mathrm{~cm}$ for Event 2 . Figure 9 also displayed that, for the same cumulative rainfall, the second rain event (Event 2) generated higher outlet runoff from the rough field plot than its earlier counterpart (Event 1). The connectivity of the rough plot was more easily achieved for Event 2. Thus, both laboratory and field experiments in this study demonstrated that a rough soil surface exhibited enhanced capability of overland flow generation in subsequent rainfall events. Similar findings also have been obtained from experimental studies by other researchers $[6,15]$ who posited that rough surfaces experienced a rising steady-state flow with subsequent rain events. Gómez and Nearing [15] concluded that higher hydraulic resistance to infiltration of a rough surface was increasing with rain events. This lower conductivity gave rise to the higher steady overland flows. 


\section{Summary and Conclusions}

A series of laboratory and field experiments with focus on evaluating the influences of surface microrelief on overland flow generation were conducted. Particularly, the combined effects of microrelief (rough and smooth surfaces), soil type (three different soils), initial soil moisture (three initial water contents), and rainfall (three single steady/unsteady rainfall events and one complex multievent rainfall) were examined and analyzed in this experimental study. Both the laboratory and field experiments and the related paired $t$-tests indicated that surface microrelief significantly influenced overland flow generation and its spatiotemporal variations. Importantly, such influences also were affected by other hydrologic factors, such as rainfall characteristics, soil properties, and initial soil moisture conditions. Whether a rough or smooth surface generated more runoff depended on the combination of these factors. In particular, the characteristics of rainfall, including its intensity (heavy and light rainfall) and its temporal variability (steady and unsteady and single and multiple events), played an important role in overland flow generation.

It was found that during an initial rainfall event or the early stage of a rainfall event, a rough surface produced less runoff than its smooth counterpart. Due to the effect of surface depressions and the related puddle filling-spillingmerging processes, initiation of surface runoff from the rough surface was delayed, which further resulted in lower runoff production during the initial rainfall event. This trend was true across the types of soil and also the range of different initial soil moisture conditions. The influence of initial water content on overland flow generation and surface runoff was observed primarily during the early stage of a rainfall event. As top soil was fully saturated and wetting front moved to deep soil, such an influence became less important. Interestingly, the rough soil surface exhibited an increasing trend in the capability of overland flow generation in subsequent rainfall events. Over the course of multiple rainfall events, the rough surface overtook the smooth surface in steadystate flows after full connectivity was achieved. The increased capability of a rough surface in overland flow generation also was observed for the later stage of a single unsteady rainfall event in both laboratory and field experiments.

The field experimental data showed that the smooth plot surface was more responsive to rainfall variations than the rough one in overland flow generation. However, the response of the rough field plot surface increased and higher runoff was produced during the later stage of the second unsteady rainfall event. Similar to the laboratory experiments, a delay in initiation of surface runoff from the rough plot was observed for both natural rainfall events due to its depressions.

\section{Conflict of Interests}

The authors declare that there is no conflict of interests regarding the publication of this paper.

\section{Acknowledgments}

This material is based upon work supported by the National Science Foundation under Grant no. EAR-0907588 and NSF EPSCoR Award IIA-1355466. The authors would like to thank Leif Sande, Abdul Namrou, Jun Yang, Yaping Chi, Yang Liu, Yingjie Yang, and Noah Habtezion for their various contributions to the related research project.

\section{References}

[1] X. Chu, J. Yang, Y. Chi, and J. Zhang, "Dynamic puddle delineation and modeling of puddle-to-puddle filling-spillingmerging-splitting overland flow processes," Water Resources Research, vol. 49, no. 6, pp. 3825-3829, 2013.

[2] I. D. Moore and C. L. Larson, "Estimating micro-relief surface storage from point data," Transactions of the American Society of Agricultural Engineers, vol. 22, no. 5, pp. 1073-1077, 1979.

[3] C. Huang and J. M. Bradford, "Portable laser scanner for measuring soil surface roughness," Soil Science Society of America Journal, vol. 54, no. 5, pp. 1402-1406, 1990.

[4] E. J. Mwendera and J. Feyen, "Estimation of depression storage and Manning's resistance coefficient from random roughness measurements," Geoderma, vol. 52, no. 3-4, pp. 235-250, 1992.

[5] E. C. Kamphorst, V. Jetten, J. Guerif et al., "Predicting depression storage from soil surface roughness," Soil Science Society of America Journal, vol. 64, pp. 1749-1758, 2000.

[6] F. Darboux and C.-H. Huang, "Does soil surface roughness increase or decrease water and particle transfers?" Soil Science Society of America Journal, vol. 69, no. 3, pp. 748-756, 2005.

[7] K. J. Mitchell and B. A. Jones Jr., "Micro-relief surface depression storage: analysis of models to describe the depth-storage function," Water Resources Bulletin, vol. 12, no. 6, pp. 1205-1222, 1976.

[8] F. Darboux and C.-H. Huang, "An instantaneous-profile laser scanner to measure soil surface microtopography," Soil Science Society of America Journal, vol. 67, no. 1, pp. 92-99, 2003.

[9] Y. Martin, C. Valeo, and M. Tait, "Centimetre-scale digital representations of terrain and impacts on depression storage and runoff," Catena, vol. 75, no. 2, pp. 223-233, 2008.

[10] T. Dunne, W. Zhang, and B. F. Aubry, "Effects of rainfall, vegetation, and microtopography on infiltration and runoff," Water Resources Research, vol. 27, no. 9, pp. 2271-2285, 1991.

[11] G. Govers, I. Takken, and K. Helming, "Soil roughness and overland flow," Agronomie, vol. 20, no. 2, pp. 131-146, 2000.

[12] B. Hansen, P. Schjønning, and E. Sibbesen, "Roughness indices for estimation of depression storage capacity of tilled soil surfaces," Soil and Tillage Research, vol. 52, no. 1-2, pp. 103-111, 1999.

[13] M. J. Abedini, W. T. Dickinson, and R. P. Rudra, "On depressional storages: the effect of DEM spatial resolution," Journal of Hydrology, vol. 318, no. 1-4, pp. 138-150, 2006.

[14] K. Helming, M. J. M. Römkens, and S. N. Prasad, "Surface roughness related processes of runoff and soil loss: a flume study," Soil Science Society of America Journal, vol. 62, no. 1, pp. 243-250, 1998.

[15] J. A. Gómez and M. A. Nearing, "Runoff and sediment losses from rough and smooth soil surfaces in a laboratory experiment," Catena, vol. 59, no. 3, pp. 253-266, 2005.

[16] L. D. Meyer and W. C. Harmon, "Multiple-intensity rainfall simulator for erosion research on row sideslopes," Transactions 
American Society of Agricultural Engineers, vol. 22, no. 1, pp. 100-103, 1979.

[17] L. D. Meyer, "Rainfall simulators for soil erosion research," in Soil Erosion Research Methods, R. Lal, Ed., CRC Press, 2nd edition, 1994.

[18] L. Sande, X. Chu, and T. DeSutter, "A new method for replicating complex microtopographic surfaces in laboratory soil box experiments," Applied Engineering in Agriculture, vol. 27, no. 4, pp. 615-620, 2011.

[19] X. Chu, J. Zhang, Y. Chi, and J. Yang, "An improved method for watershed delineation and computation of surface depression storage," in Watershed Management 2010: Innovations in Watershed Management under Land Use and Climate Change, Proceedings of the 2010 Watershed Management Conference, $\mathrm{K}$. W. Potter and D. K. Frevert, Eds., pp. 1113-1122, American Society of Civil Engineers, 2010. 

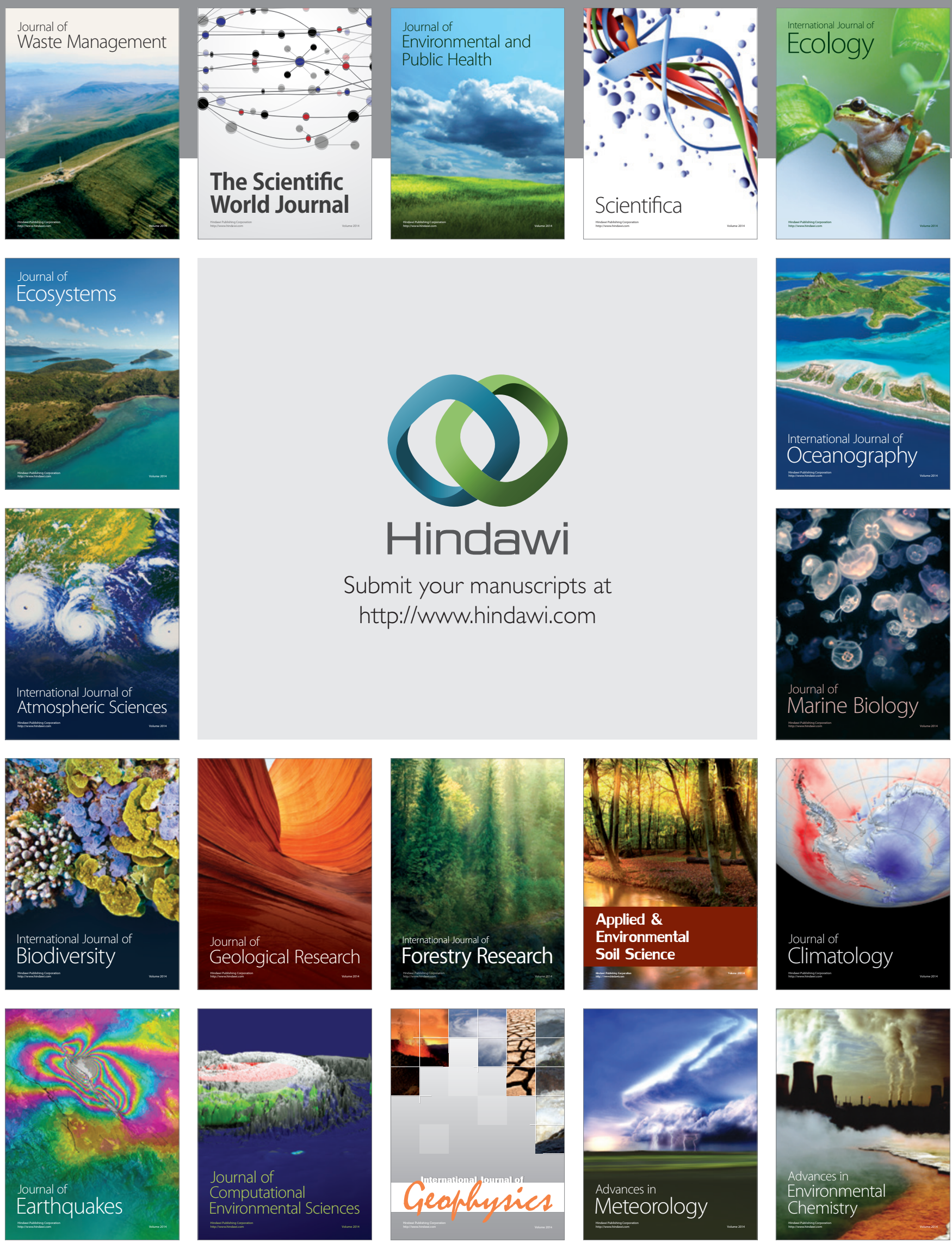